\title{
A Pencil in Spinal Canal-penetrating Injury-Endoscopic Management
}

\author{
Vivek Agrawal ${ }^{1} \quad$ Kailash Rathod $^{2} \quad$ Ranjit Rangnekar ${ }^{1}$ \\ ${ }^{1}$ Department of Neuroscience, Sir H N Reliance Foundation hospital \\ and Research Centre, Mumbai, Maharashtra, India \\ 2Department of Anaesthesia, Jankalyan Hospital, Kalyan, Thane, \\ Maharashtra, India

\begin{abstract}
Address for correspondence Vivek Agrawal, MCh, Department of Neurosurgery, Sir. H N Reliance Foundation hospital and Research Centre, Mumbai 40004, Maharashtra, India
\end{abstract} \\ (e-mail: neuro.vi@gmail.com).
}

Indian J Neurosurg 2021;1:74-76.

\begin{abstract}
Penetrating spinal trauma is a rare event and mostly occurs as a result of assault or accident. There is no specific management protocol about such injuries. We are reporting a case of spinal trauma in a child of 6 years, who encountered a penetrating injury to the lower back when he fell over a sharp pencil. It resulted in a penetrating wound in the lower back with half of the broken pencil fragment lodged deep into the wound. There was a watery discharge from the wound with severe backache and radiating pain in both lower limbs. On clinical examination, motor power of both lower limbs was 5/5 (Medical Research Council [MRC] grade) with intact sensation and severely restricted straight leg raise (SLR). Imaging revealed a large fragment of pencil lodged in the spinal canal at $L 4$ vertebral level. Surgical removal of foreign bodies and dura repair was done with endoscope and without laminectomy. The backache and lower limb pain

Keywords

- penetrating injury

- endoscope

- spinal canal relieved completely with healing of puncture site. In this case, the endoscopic technique enabled us to direct visualize penetration tract, injured structures, removal of foreign bodies and hematoma with repair of dura and without doing a destabilizing bone cutting and tissue damage.
\end{abstract}

\section{Introduction}

Penetrating spinal trauma is a rare event and mostly occurs as a result of assaults or accidents. There is no specific management protocol about such injuries. We are reporting a rare case of accidental penetrating spinal trauma in a 6-year-old male child, which underwent a unique management by way of the endoscopic approach. There are very few case reports of endoscopic management of penetrating spinal injuries in literature. ${ }^{1}$

\section{Case Report}

A 6-year-old male child encountered an accidental penetrating injury to the lower back when he fell over a sharp pencil

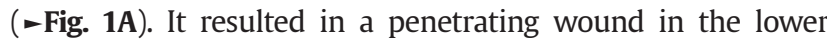
back, with half of the broken pencil fragment lodged deep into the wound. There was a watery discharge from the wound with severe backache and radiating pain in both lower limbs.

DOI https://doi.org/ $10.1055 / \mathrm{s}-0040-1717822$ ISSN 2277-954X.
The child was taken to a general practitioner, where he sutured the punctured wound, and shifted the child to our center for further management. On clinical examination, motor power of both lower limbs were 5/5 (Medical Research Council [MRC] grade) with intact sensation and severely restricted straight leg raise (SLR). Sphincter functions were intact. CT and MRI of lumbosacral spine were done and it revealed a large fragment of pencil extending tangentially from subcutaneous level at S3 vertebra to interlaminar space at L5-S1 vertebra and in side spinal canal up to L4 vertebra posterior surface ( - Fig. 1 B-E). On local examination, the foreign body was palpable quite rostral to puncture site. We had two options of surgery in this case

A. Removal of foreign body with laminectomy to inspect inside the spinal canal for any fragments and dural repair.

B. Removal of foreign body with endoscopic inspection of spinal canal to remove fragments and dural repair

This is an open access article published by Thieme under the terms of the Creative Commons Attribution-NonDerivative-NonCommercial-License, permitting copying and reproduction so long as the original work is given appropriate credit. Contents may not be used for commercial purposes, or adapted, remixed, transformed or built upon. (https://creativecommons.org/licenses/by-nc-nd/4.0/)

Thieme Medical and Scientific Publishers Pvt. Ltd., A-12, 2nd Floor, Sector 2, Noida-201301 UP, India 
We decided to do it with endoscopic technique, wherein incision was taken after confirming vertebral level of foreign body fragment under $\mathrm{C}$ arm (-Fig. 1F). There was a cerebrospinal fluid (CSF) leak after removal of pencil fragment ( - Fig. 2 A-C). A $5 \mathrm{~mm}$ endoscope was negotiated through the same interlaminar puncture site. Multiple pieces of pencil coating paint debris and hematoma were removed from inside the canal with help of an endoscope and without doing laminectomy (-Fig. 2 D-G). Dura was repaired with approximation stitches and fibrin glue, followed by meticulous fascial closure. A copious amount of normal saline wash was given during the procedure. Postoperatively, the child recovered well. His back and lower limb pain were resolved. Surgical site and punctured wound healed well. Postop CT scan was done, which ruled out any remnant of foreign body.

\section{Discussion}

Majority of penetrating spinal traumas are due to high- or low-velocity missile injuries but a significant proportion is due to nonmissile penetrating traumas ${ }^{2}$. Nonmissile penetrating injuries are due to road traffic accidents, stab assaults, or a fall
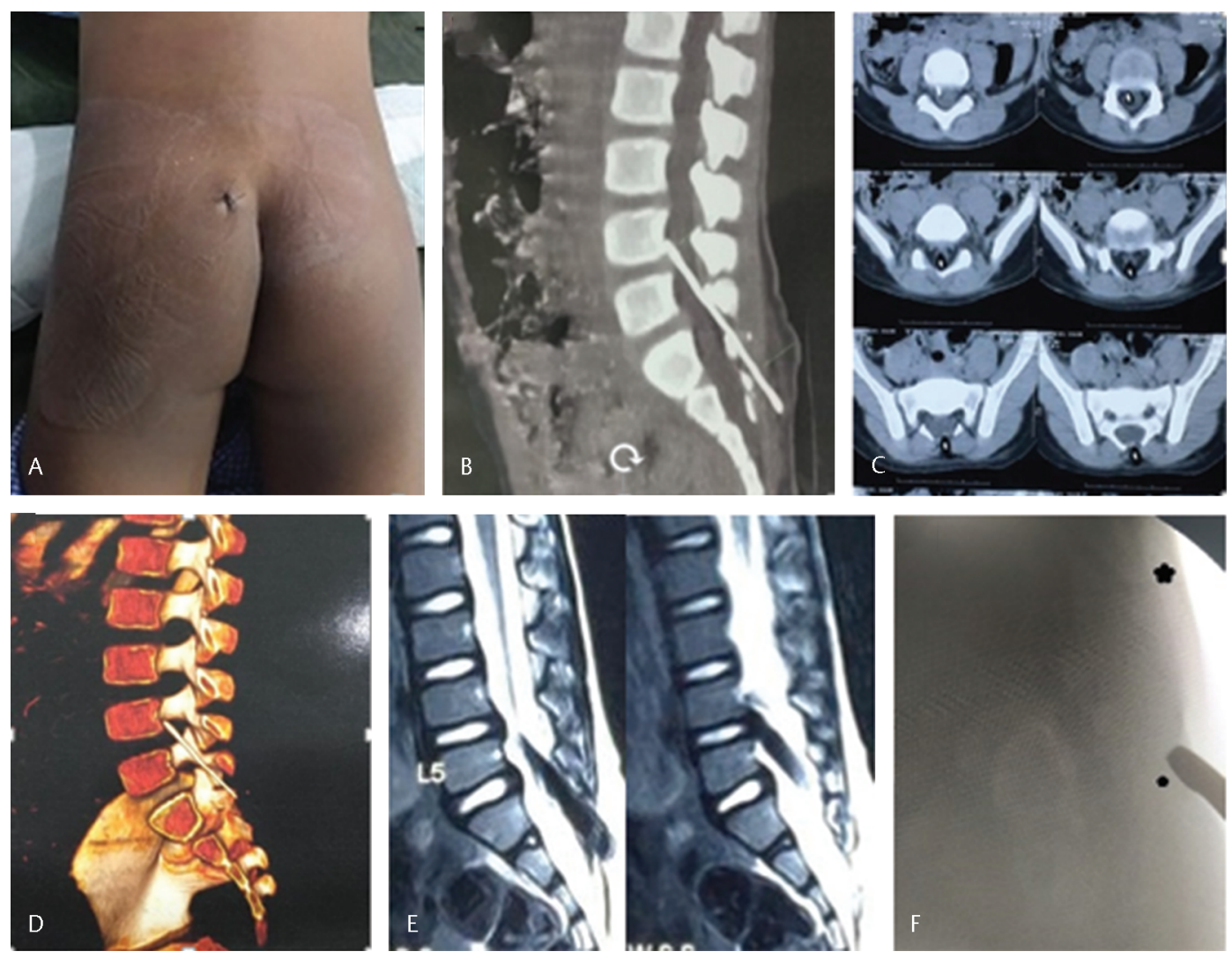

Fig. 1 (A) Puncture site of penetrating injury. (B) CT scan sagittal view-pencil tangential trajectory to spinal canal at L4 level. (C) CT scan axial cuts. (D) 3D reconstruction. (E) MRI sagittal cuts-foreign body at L4 vertebral level. (F) Intraoperative C-arm image. ${ }^{*}$ Foreign body. ${ }^{*}$ Marker at puncture site.
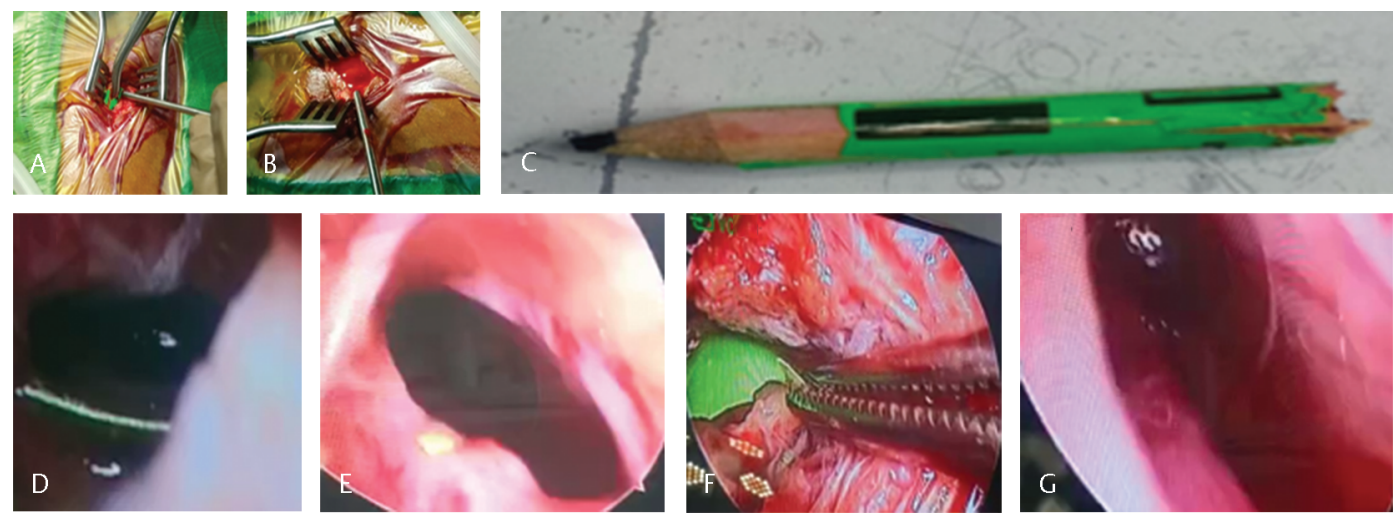

Fig. 2 (A) Removal of foreign body. (B) Cerebrospinal fluid (CSF) leak from wound after removal of foreign body. (C) Extracted broken lead pencil. (D) Debris in spinal canal. (E) Debris in epidural space. (F) Debris of pencil paint in penetrating tract. (G) Visualization of hematoma in spinal canal. 
over a sharp object. It is common among the male population and in the dorsal spinal segment, followed by lumbar and cervical due to relative difference in segmental length. ${ }^{3}$ Thorough neurological and local examinations of all these patients are very crucial, as management of these patients depends solely on clinical findings. Radiological imaging in these cases requires a CT scan to evaluate fractures, canal compromise, foreign bodies, and spinal alignment. MRI may be useful to assess ligamentous and spinal cord damage, hematoma and foreign bodies. ${ }^{4,5}$ Surgery is indicated in cases with spinal instability, excessive CSF leak, clear demonstration of a projectile bone fragment or foreign body, and spinal hematoma causing a neurological deficit or intractable pain. ${ }^{5}$ In our case, surgery was indicated as there was CSF leak due to fragment of the pencil deep inside the spinal canal, causing intractable pain.

Surgical exploration of penetrating spinal wounds should be carefully weighed against the possibility of difficult dural closure and other complications. Therefore, in most instances, unless a clear compressive lesion is identified (i.e., hematoma or bone or foreign body), nonsurgical management is the more prudent strategy. Many of these patients may worsen later due to complications in form of CSF leak, discitis, osteomyelitis, or abscess formation. ${ }^{6}$

The conventional approach in penetrating spinal injury requires a wound exploration, removal of foreign body, bony fragments and hematoma from canal, exposure and repair of dural tear, and fixation in cases of instability. In our case, there was a tangential tract from subcutaneous plan to vertebral body, so complete exposure might have required a laminectomy at L4/5 level to achieve removal of foreign body and dural repair, but endoscopic technique enabled us to achieve it without a laminectomy and a large surgical wound in a young child. The advantage of endoscopic treatment involves direct evaluation of injured structures and management without excessive tissue damage and destabilization. We encountered certain technical difficulties also during his procedure, for example, water-tight dural repair and removal of migrated foreign body from spinal canal.

\section{Conflict of Interest}

None declared.

\section{Acknowledgment}

The authors are thankful to Arnav Agrawal for his assistance in editing and submission of manuscript.

\section{Reference}

1 Long ZS, Nie XY, Zhang YW. Treatment of penetrating trauma to the buttock assisted by spinal endoscopy. J Int Med Res 2020;48(1):300060519887303

2 Velmahos GC, Degiannis E, Hart K, Souter I, Saadia R. Changing profiles in spinal cord injuries and risk factors influencing recovery after penetrating injuries. J Trauma 1995;38(3):334-337

3 Simpson RK Jr, Venger BH, Narayan RK. Treatment of acute penetrating injuries of the spine: a retrospective analysis. J Trauma 1989;29(1):42-46

4 Rall JM, Gebremariam FA, Joubert G. Imaging findings of penetrating spinal cord injuries secondary to stab wounds on magnetic resonance imaging in a tertiary trauma unit, South Africa. SA J Radiol 2019;23(1):1761

5 Manzone P, Domenech V, Forlino D. Stab injury of the spinal cord surgically treated. J Spinal Disord 2001;14(3):264-267

6 Kulkarni AV, Bhandari M, Stiver S, Reddy K. Delayed presentation of spinal stab wound: case report and review of the literature. J Emerg Med 2000;18(2):209-213 